\title{
Desain dan Implementasi Akuisisi Data Suhu Murid Sekolah Berbasis Arduino Untuk Monitoring Kesehatan Komunal
}

\author{
Munaf Ismail*, Sri Arttini Dwi Prasetyowati, dan Jenny Putri Hapsari \\ Program Studi Teknik Elektro, Fakultas Teknologi Industri, Universitas Islam Sultan Agung \\ "Corresponding author, e-mail: munaf@unissula.ac.id
}

\begin{abstract}
Abstrak - Banyak penyakit berbahaya yang ditandai dengan naiknya suhu tubuh manusia, seperti demam berdarah dengue, difteri dan banyak lagi. Pada periode Januari 2019 terjadi 1.204 kasus demam berdarah dengue di Jawa Tengah dan sebagian besar terjadi pada anak usia sekolah dasar. Penyakit berbahaya lain yang menimpa anak-anak pernah terjadi pada tahun 2018, timbul endemi difteri pada satu sekolah dasar di Semarang yang mengakibatkan 2 siswa meninggal dan 5 siswa lainnya dirawat di rumah sakit. Pemeriksaan suhu tubuh atau kesehatan secara berkala menjadi penting kususnya anak-anak untuk deteksi dini dan mencegah timbulnya penyakit berbahaya. Penelitian ini merancang dan mengimplementasikan sensor suhu MLX90614 yang terintegrasi dengan sensor fingerprint berbasis arduino serial komputer sebagai akuisisi data suhu tubuh dan kehadiran anak didik sekolah. Komputer berfungsi penyimpan database pengukuran suhu dan kehadiran siswa, sehingga user mudah dimonitor melalui layar komputer. Hasil pengukuran menunjukkan hasil yang baik karena kesalahan rata-rata pengukuran suhu di bawah 5\%. Kesalahan terbesar adalah 3,41\% dan terendah adalah 2,01\%. Hasil pengukuran juga menunjukkan nilai presisi tertinggi 95,88\% dan akurasi tertinggi 99,24\%. Akuisisi data suhu dan kehadiran siswa akan berfungsi sebagai deteksi dini demam serta pemeriksaan kesehatan berkala sebagai upaya bersama untuk menjaga kesehatan anak-anak sekolah generasi penerus bangsa.
\end{abstract}

Kata Kunci : Akuisisi Data, Sensor suhu, Fingerprint, Arduino serial komputer

\begin{abstract}
Many dangerous diseases are characterized by increases in human body temperature, such as dengue hemorrhagic fever, diphtheria and more. In the period of January 2019 there were 1,204 cases of dengue hemorrhagic fever in Central Java and most of them occurred in elementary school age children. Other dangerous diseases that afflict children have occurred in 2018, there are endemic diphtheria in an elementary school in Semarang which resulted in 2 students dying and 5 other students being hospitalized. Regular checks of temperature or health are important especially for children to prevent dangerous diseases. This study designed and implemented the MLX90614 body temperature sensor which was integrated with the Arduino serial computer fingerprint sensor as body temperature data acquisition and school student attendance. The computer functions as a database storage for temperature measurement and student attendance, so that it is easily monitored through a computer screen. The measurement results showed good results because the temperature measurement errors were below $5 \%$ on average. The biggest mistake was $3.41 \%$ and the lowest was $2.01 \%$. The measurement results also showed the highest precision value of $95.88 \%$ and the highest accuracy of $99.24 \%$. Temperature data acquisition and student attendance will function as early detection of fever and periodic health checks as a joint effort to maintain the health of the next generation of school children.
\end{abstract}

Keywords : Data acquisition, Temperature sensor, Fingeprint, Arduino serial computer

\section{Pendahuluan}

Kenaikan suhu tubuh biasanya terjadi dikarenakan flu biasa. Akan tetapi banyak penyakit berbahaya lainya yang ditandai dengan naiknya suhu tubuh manusia, seperti bronkopneumonia, demam typhoid,demam berdarah dengue [1], difteri [2] dan masih banyak penyakit berbahaya lainya.
Periode januari 2019 penyakit demam berdarah dengue ditemukan 1.204 kasus di Provinsi Jawa Tengah [3]. Jumlah kasus demam berdarah dengue di Jawa Tengah termasuk 4 besar di wilayah Indonesia dalam jumlah kasus terbesar penyakit ini. Sebagian besar kasus demam berdarah dengue terjadi pada usia 1 - 14 tahun yaitu usia anak pra

Received date 2019-06-19, Revised date 2019-06-25, Accepted date 2019-07-24 
sekolah-sekolah dasar. Penyakit ini ditandai dengan demam selama 2 - 3 hari dan muncul bitnik-bintik merah pada kulitnya. Deteksi dini demam pada anak-anak menjadi sangat penting, kususnya pada lingkungan sekolah pendidikan usia dini - sekolah dasar yang banyak terjadi kasus demam berdarah.

Pada tahun 2018 pada salah satu sekolah dasar di kecamatan Genuk kota Semarang terjadi endemi dimana 2 siswanya meninggal dunia dan 5 siswa lainya dirawat rumah sakit karena terkena penyakit difteri. Kejadian-kejadian meninggalnya siswa didik dapat dihindari apabila ada kesadaran menjaga kesehatan bersama dan pemeriksaan berkala pada siswa baik di lingkungan rumah ataupun dilingkungan sekolah.

Pengukuran suhu tubuh biasanya menggunakan thermometer. Beberapa jenis thermometer yang biasanya digunakan adalah thermometer air raksa, thermometer digital dan thermometer infra merah. World Health Organization (WHO) dan Health Care Without Harm $(\mathrm{HCWH})$ berencana mengganti 70 persen dari semua termometer raksa di seluruh dunia dengan alternatif digital pada 2017 berupa thermometer digital dan infra merah karena akurat dan mudah digunakan [4]. Penelitian yang dilakukan pada tahun 2014 pada neonatus dinyatakan bahwa thermometer inframerah / noncontact thermometer merupakan metode pengukuran yang cepat dan mudah, namun masih dipengaruhi oleh beberapa faktor dalam pengukurannya Kelebihan lain dari non-contact thermometer infra merah karena tidak ada sentuhan langsung ke tubuh yang diukur.

Fingerprint merupakan sidik jari manusia yang berfungsi sebagai identifikasi manusia karena pola sidik jari yang berbeda pada setiap manusia. Identitas dengan sidik jari didukung dengan teknologi dikenal sebagai biometric. Alat absensi sidik jari biasanya digunakan untuk mesin absensi atau untuk kontrol lainya seperti kendali pintu masuk, palang portal dan banyak lagi.

Pada kesempatan kali ini penulis merancang alat ukur suhu tubuh dengan mengintegrasikan ke mesin absensi fingerprint. Karena kesibukan dan aktifitas yang tinggi manusia terkadang tidak memperhatikan perubahan suhu tubuhnya dirinya atau keluarganya. Hal ini menjadi penting kususnya pada anak-anak yang belum bisa memahami demam tubuhnya. Diharapkan dengan sidik jari yang dikombinasi dengan fungsi sensor suhu noncontact thermometer infra merah akan menambah fungsi absensi fingerprint sebagai sistem data akuisisi suhu tubuh, saat absensi fingerprint siswa sekolah dapat absen kehadiran dan sekaligus mengecek suhu tubuhnya sehingga apabila suhu tubuhnya melebihi suhu normal $38^{\circ} \mathrm{C}$ [5], akan dicatat dan menjadi laporan guru wali sekolahnya. Dengan tampilan LCD dan layar monitor yang menampilkan nama siswa yang absen dan suhu tubuhnya saat siswa tersebut meletakan sidik jarinya di aplikasi fingerprint dan sensor suhu, perangkat ini menggunakan komunikasi serial komputer yang tersambung ke arduino untuk merekam data suhu tubuh selama rentang yang panjang bisa sampai setahun guna dicatat dan dianalisa selanjutnya memberikan peringaan kepada guru wali murid sekolah atau orang tua siswa. Sistem yang dibuat berguna bagi kelompok pengguna agar lebih memperhatikan kondisi suhu tubuh siswa sekolah sebagai usaha menjaga kesehatan komunal untuk mencegah penyakit yang lebih berbahaya yang dapat berbahaya bagi anakanak kita.

\section{Tinjauan Pustaka}

\subsection{Sistem Akuisisi Data}

Definisi akuisisi data yaitu suatu sistem yang berfungsi untuk mengambil, mengumpulkan, dan menyiapkan data, hingga memprosesnya untuk menghasilkan data yang dikehendaki, seperti yang ditunjukkan pada Gambar 1. Akuisisi data adalah proses sampling dari kondisi nyata fisik dunia dan mengkonversi dari masukan sampel yang dihasilkan menjadi keluaran nilai numerik digital untuk dimanipulasi komputer. Beberapa komponen dari sistem akuisisi data meliputi sensor-sensor untuk membaca besaran fisik, Data Acquisition (DAQ) untuk mengkonversi parameter fisik untuk sinyal listrik, komputer akan mengumpulkan dan menampilkan data yang dikehendaki.

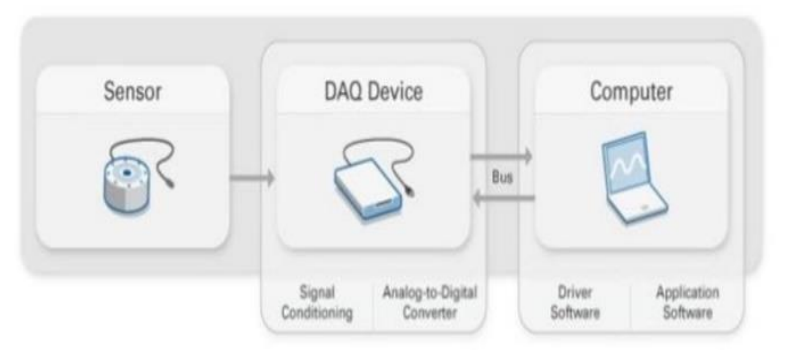

Gambar 1.Diagram Blok Sistem Akuisisi Data [6]. 


\subsection{Arduino}

Arduino adalah sebuah board mikrokontroler berbasis ATmega328. Gambar 2 menunjukkan sebuah Arduino yang memiliki 14 pin input/output yang mana 6 pin dapat digunakan sebagai output PWM, 6 analog input, crystal oscilator $16 \mathrm{MHz}$, koneksi USB, jack power, kepala ICSP, dan tombol reset. Arduino mampu men-support mikrokontroler. Arduino berfungsi sebagai sistem pengendali, pemproses data serta mengirimkan data ke komputer [7].

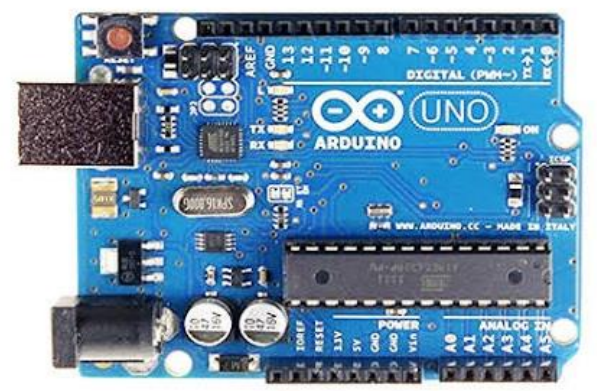

Gambar 2. Mikrokontroler Arduino Uno

\subsection{Fingerprint}

Sensor sidik jari yang gunakan dalam pembuatan penelitian ini adalah sensor sidik jari optikal, yang berguna mendeteksi sidik jari dengan verifikasi yang sangat sederhana seperti yang ditunjukkan pada Gambar 3. Modul sensor ini bekerja dengan otak utama berupa chip DSP (Digital Signal Processor) yang melakukan proses image rendering, kemudian mengkalkulasi, feature-finding dan terakhir searching pada data yang sudah ada.

Output sensor ini berupa TTL (TransistorTransistor Logic) serial, yang memungkinkan untuk dihubungkan dengan Arduino maupun mikrokontroler lainnya. Produk ini berguna menyimpan data hingga 162 sidik jari pada flash memory internal-nya. Modul fingerprint ini dilengkapi dengan LED merah pada lensa yang akan menyala sebagai indikator ketika pengambilan gambar berlangsung.

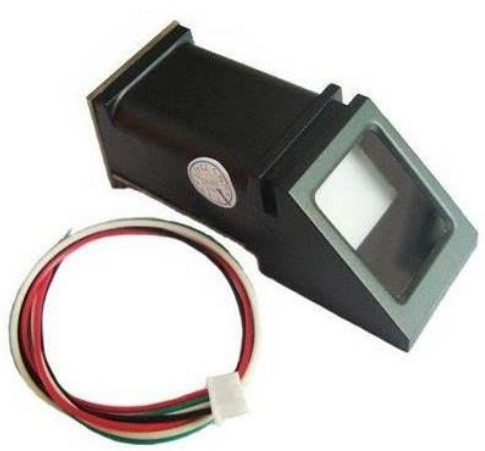

Gambar 3. Modul fingerprint

\subsection{Sensor MLX90614}

Sensor MLX90614, jenis sensor yang dipakai pada penelitian ini bekerja pada tegangan masukan sebesar 3,3 Volt. Sensor ini memiliki 4 kaki seperti yang ditunjukkan pada gambar 4. Kaki VCC dihubungkan ke pin tegangan 3,3 Volt Arduino, kaki SCL (serial clock) dihubungkan ke pin input A5, kaki SDA (serial data) dihubungkan ke pin input A4 dan kaki ground dihubungkan ke pin ground pada Arduino [7].

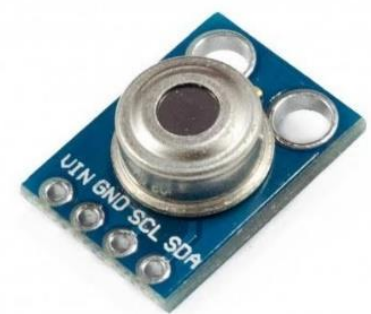

Gambar 4. Non contact thermometer MLX90614

\section{Metodologi Penelitian}

\subsection{Perancangan Sistem}

Metode penelitian dilakukan dalam 3 tahap yaitu tahap rancang bangun sistem monitoring suhu dan kehadiran siswa, pengujian sistem monitoring suhu dan kehadiran siswa, terakhir adalah implementasi sistem. Tahapan penelitian secara lengkap dapat dilihat pada gambar 5 . 


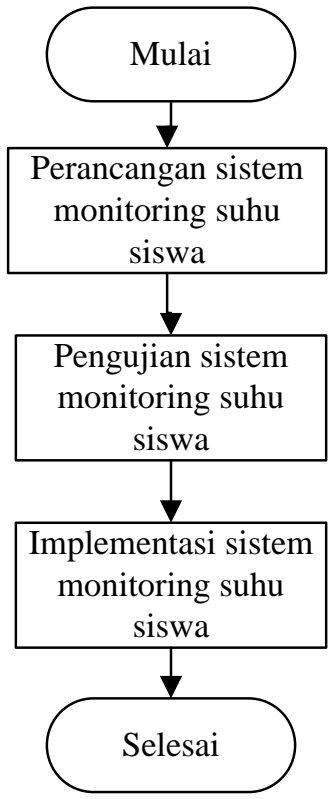

Gambar 5. Tahapan penelitian

Perancangansistem akuisisi data monitoring suhu dan kehadiran siswa seperti blok diagram pada gambar 6. Terdiri dari hardware berupa sensor suhu tubuh menggunakan sensor MLX90614, modul fingerprint untuk absensi sidik jari dan arduino untuk membaca data suhu dan kehadiran siswa untuk diteruskan secara serial ke komputer. Software aplikasi Fingerprint attandance di komputer berguna untuk mengumpulkan dan menyimpan database suhu tubuh dan kehadiran siswa.

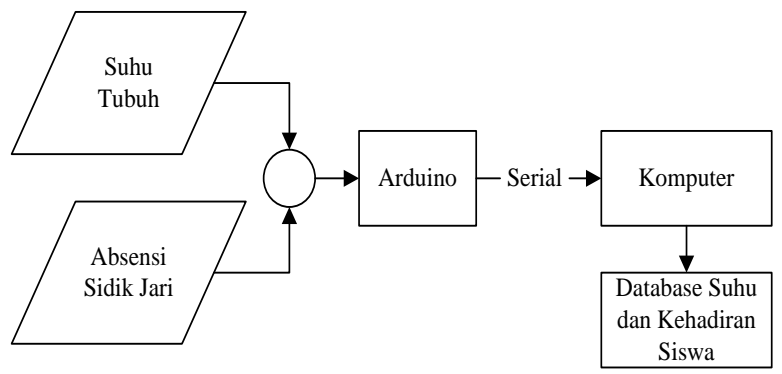

Gambar 6. Blok Diagram Sistem Akuisi Data Suhu dan Absensi Kehadiran Siswa

\subsection{Perancangan Hardware}

Dari perancangan hardware sistem monitoring suhu dan kehadiran siswa menggunakan beberapa komponen seperti berikut: mikrokontroler ATMega 328 (pada modul Arduino Uno), sensor suhu tubuh MLX90614, modul fingerprint dan komputer yang terhubung serial dengan arduino. Seperti terlihat pada gambar 7 berikut ini.

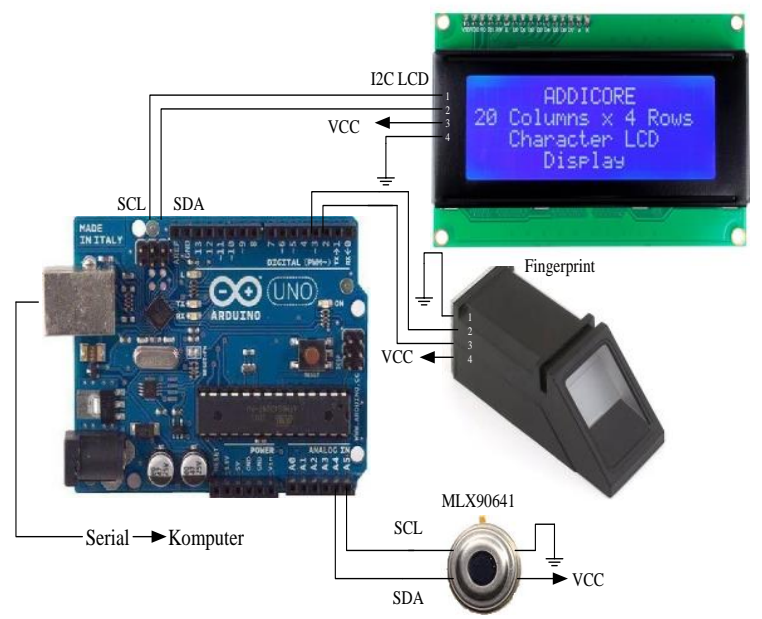

Gambar 7. Konfigurasi hardware pembaca suhu tubuh dan kehadiran siswa

Penelitian sistem akuisisi data monitoring suhu dan kehadiran siswa menggunakan sensor suhu MLX90614 untuk membaca suhu siswa dan sensor fingerprint untuk mendeteksi kehadiran siswa sekolah. Pertama siswa masuk dan pulang sekolah akan di baca absensi kehadiranya dengan sensor fingerprint selanjutnya dibaca temperature suhu siswa pada saat itu dan akan tersimpan di komputer. Apabila suhu tubuh siswa pada melebihi $38^{\circ} \mathrm{C}$ selama dua hari akanditeruskansebagai informasi untuk guru dan orang tuanya untuk memeriksa kesehatan siswa lebih lanjut sebagai pencegahan penyakit berbahaya.

\subsection{Perancangan Software}

Dalam penelitian ini juga dibangun software aplikasi fingerprint attendance sebagai interface dengan menggunakan bahasa pemrogaman visual c\# dan penyimpanan data menggunakan sqlite. Aplikasi ini berfungsi membaca data suhu dan kehadiran siswa yang dibaca oleh sensor dan mikrokontroler di arduino untuk dibaca dan disimpan di komputer melalui jalur komunikasi serial antara komputer dan arduino.

Interface pada aplikasi fingerprint attendanace terdapat beberapa informasi diantaranya dari sensor suhu, modul fingerprint dan aplikasi ini juga dapat menampilkan rekap kehadiran siswa per kelas. 


\section{Hasil dan Pembahasan}

Hardware monitoring suhu dan kehadiran siswa terdiri dari mikrokontroler ATMega 328 yang ada di Arduino sebagai pengendali modul fingerprint dan sensor suhu MLX90614 seperti yang ditunjukkan pada Gambar 8. Letak sensor sidik jari dan sensor suhu MLX90614 berdekatan. Cara kerjanya adalah mikrokontroler membaca modul fingerprint ketika siswa absensi. Pembacaan sidik jari dicocokan namanya dengan data yang sudah direkam, kemudian diukur suhu tubuhnya oleh sensor non-contact thermometer MLX90614 melalui jari yang digunakan untuk absensi. Nama, suhu tubuh dan waktu masuk atau pulang sekolah direkap sebagai database di komputer.

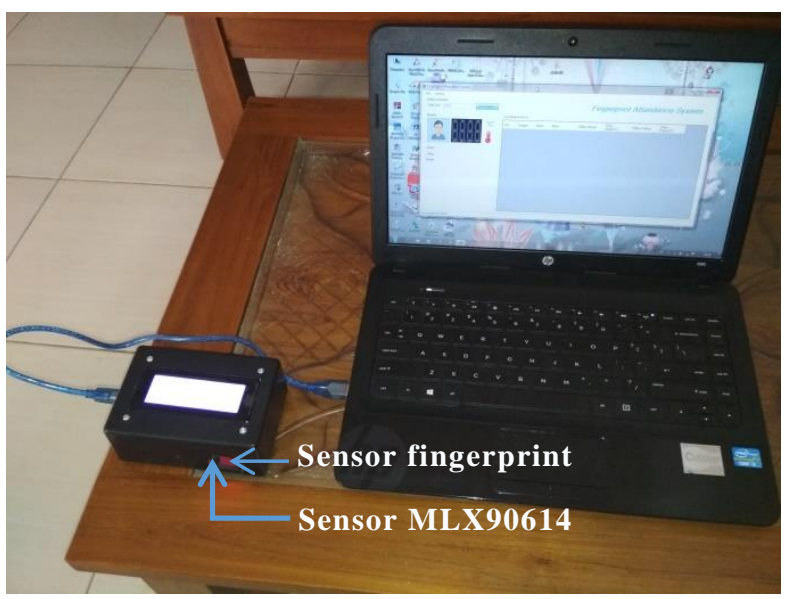

Gambar 8. Sistem monitoring suhu dan kehadiran siswa

Pengujian sistem monitoring suhu dan kehadiran siswa dilakukan melalui pembacaan suhu dan kehadiran siswa oleh aplikasi fingerprint attendance yang dibaca dari sensor. Software aplikasi ini menggunakan pemrogaman visual $\mathrm{c \# .}$ Tampilan pembacaan suhu siswa dan kehadiran siswa terlihat pada gambar 9 .

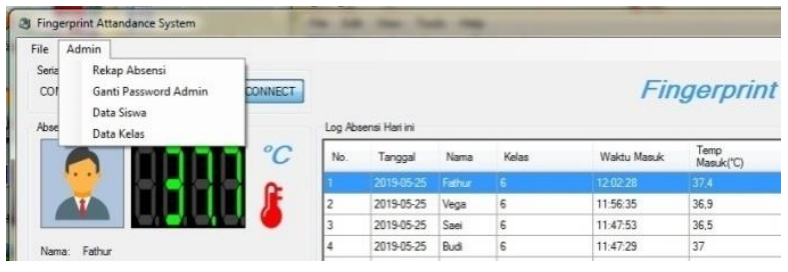

Gambar 9. Tampilan aplikasi fingerprint attendance menampilkan rekap absensi dan suhu siswa
Aplikasi fingerprint attendance berhasil menampilkan pembacaan absensi dan suhu tubuh siswa sehingga dapat monitoring kehadiran dan suhu tubuh siswa secara berkelanjutan.

Data pengukuran yang dilakukan menggunakan aplikasimonitoring suhu dan kehadiran siswa hasil penelitiandibandingkan dengan pengukuran menggunakan thermometer digital infrared pabrikan sebagai referensi pengukuran didapat hasil seperti tabel 1 berikut ini.

Tabel 1. Perbandingan suhu siswa saat masuk sekolah

\begin{tabular}{|c|c|c|c|c|c|}
\hline Siswa & $\begin{array}{c}\text { Thermometer } \\
\text { digital } \\
\text { infrared } \\
\text { referensi }\left({ }^{\circ} \mathrm{C}\right)\end{array}$ & $\begin{array}{c}\text { Aplikasi } \\
\text { monitoring } \\
\text { suhu }\left({ }^{\circ} \mathrm{C}\right)\end{array}$ & $\begin{array}{c}\text { Error } \\
(\%)\end{array}$ & $\begin{array}{c}\text { Presisi } \\
(\%)\end{array}$ & $\begin{array}{c}\text { Akurasi } \\
(\%)\end{array}$ \\
\hline $\mathrm{A}$ & 36.8 & 37.4 & 1.63 & 96.56 & 98.10 \\
$\mathrm{~B}$ & 36.6 & 36.9 & 0.82 & 98.28 & 98.64 \\
$\mathrm{C}$ & 36.7 & 36.5 & 0.54 & 98.85 & 98.37 \\
$\mathrm{D}$ & 36.6 & 37.0 & 1.09 & 97.71 & 98.64 \\
$\mathrm{~F}$ & 36.8 & 37.1 & 0.82 & 98.28 & 98.10 \\
$\mathrm{G}$ & 36.8 & 36.9 & 0.27 & 99.43 & 98.10 \\
$\mathrm{H}$ & 36.4 & 36.7 & 0.82 & 98.28 & 99.18 \\
$\mathrm{I}$ & 37.0 & 37.5 & 1.35 & 97.13 & 97.57 \\
$\mathrm{~J}$ & 36.8 & 37.0 & 0.54 & 98.85 & 98.10 \\
$\mathrm{~K}$ & 36.8 & 36.9 & 0.27 & 99.43 & 98.10 \\
\hline
\end{tabular}

Dari tabel 1 hasil perbandingan pengukuran kita tampilkan dalam bentuk grafik seperti terlihat pada gambar 10 berikut ini.

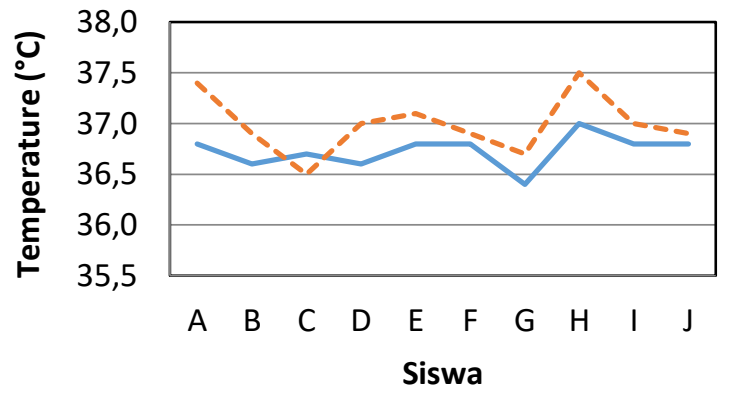

$$
\begin{aligned}
& \text { Thermometer digital infrared referensi }\left({ }^{\circ} \mathrm{C}\right) \\
& \ldots-\ldots \text { Aplikasi monitoring suhu }\left({ }^{\circ} \mathrm{C}\right)
\end{aligned}
$$

Gambar 10. Grafik perbandingan suhu siswa saat masuk sekolah

Selain perbandingan pengukuran dicari juga nilai error, akurasi dan presisi dari table 1 menggunakan persamaan berikut: 


$$
\begin{aligned}
& \text { Error }=100 \%\left(\frac{X-X_{\text {reference }}}{X_{\text {Reference }}}\right) \\
& \text { Akurasi }=100 \%\left(1-\frac{\text { Bias }+3 \sigma}{X_{\text {Reference }}}\right) \\
& \text { Presisi }=100 \%\left(1-\frac{3 \sigma}{\bar{X}}\right)
\end{aligned}
$$

Dimana $X$ adalah nilai pengukuran monitoring suhu, $X_{\text {reference }}$ adalah pengukuran pembanding dengan thermometer infrared digital, Bias adalah selisih pengukuran pembanding dan rata-rata pengukuran, $\sigma$ adalah standart deviasi dan $\bar{X}$ adalah rata-rata pengukuran [8].

Hasil perhitungan dari table 1 didapat nilai error tertinggi sebesar $1,63 \%$ dan nilai error terendah sebesar $0,27 \%$. Nilai presisi tertinggi $99,43 \%$ dan nilai presisi terendah sebesar $96,56 \%$. Sedangkan nilai akurasi tertinggi sebesar $99,18 \%$ dan nilai akurasi terendah sebesar $97,57 \%$.

Tabel 2 menunjukan hasil perbandingan antara pengukuran suhu dengan thermometer digital referensi dan pengukuran suhu dengan aplikasi penelitian saat siswa pulang sekolah, didapat hasil sebagai berikut:

Tabel 2. Perbandingan suhu siswa saat pulang sekolah

\begin{tabular}{|c|c|c|c|c|l|}
\hline $\begin{array}{c}\text { Sisw } \\
\text { a }\end{array}$ & $\begin{array}{c}\text { Thermometer } \\
\text { digital } \\
\text { infrared } \\
\text { referensi }\left({ }^{\circ} \mathrm{C}\right)\end{array}$ & $\begin{array}{c}\text { Aplikasi } \\
\text { monitoring } \\
\text { suhu }\left({ }^{\circ} \mathrm{C}\right)\end{array}$ & $\begin{array}{c}\text { Error } \\
(\%)\end{array}$ & $\begin{array}{c}\text { Presisi } \\
(\%)\end{array}$ & $\begin{array}{l}\text { Akurasi } \\
(\%)\end{array}$ \\
\hline $\mathrm{A}$ & 37.1 & 37.7 & 1.62 & 96.57 & 96.46 \\
$\mathrm{~B}$ & 36.6 & 37.5 & 2.46 & 94.86 & 97.78 \\
$\mathrm{C}$ & 36.4 & 36.5 & 0.27 & 99.43 & 98.32 \\
$\mathrm{D}$ & 36.1 & 36.5 & 1.11 & 97.71 & 99.13 \\
$\mathrm{~F}$ & 36.5 & 36.6 & 0.27 & 99.43 & 98.05 \\
$\mathrm{G}$ & 36.8 & 37.1 & 0.82 & 98.29 & 97.25 \\
$\mathrm{H}$ & 36.8 & 37.4 & 1.63 & 96.57 & 97.25 \\
$\mathrm{I}$ & 37.0 & 37.2 & 0.54 & 98.86 & 96.72 \\
$\mathrm{~J}$ & 37.0 & 37.5 & 1.35 & 97.14 & 96.72 \\
$\mathrm{~K}$ & 36.8 & 37.1 & 0.82 & 98.29 & 97.25 \\
\hline
\end{tabular}

Perbandingan pengukuran suhu siswa pulang sekolah tampilkan dalam bentuk grafik seperti terlihat pada gambar 11 .

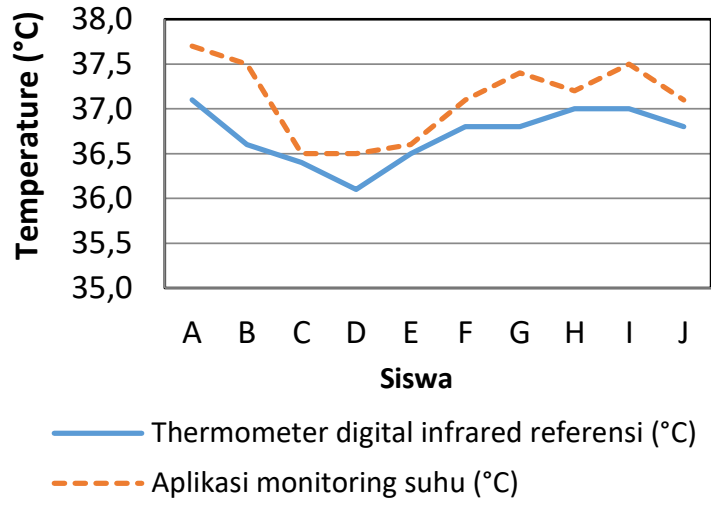

Gambar 11. Grafik perbandingan suhu siswa pulang sekolah

Hasil perhitungan dari table 2 didapat nilai error tertinggi sebesar $2,46 \%$ dan nilai error terendah sebesar $0,27 \%$. Nilai presisi tertinggi $99,43 \%$ dan nilai presisi terendah sebesar $94,86 \%$. Sedangkan nilai akurasi tertinggi sebesar $99,13 \%$ dan nilai akurasi terendah sebesar $96,46 \%$.

Dari table 1 dan 2 kita dapat melihat ada sedikit perbedaan dari pengukuran suhu dengan aplikasi monitoring suhu dan kehadiran diabndingkan dengan menggunakan thermometer digital infrared komersial. Nilai error yang dihasilkan dari kedua pengukuran diatas menunjukan Error maksimal yang dihasilkan adalah $2,46 \%$ nilai ini masih dibawah 5\% sehingga dikatakan pengukuran masih baik menurut Badan Pengaman Fasilitas Kesehatan (BPFK) [9].

Apabila suhu tubuh siswa demam atau lebih dari $38^{\circ} \mathrm{C}$ selama dua hari berturut-turut, informasi tersebut dapat disampaikan kepada guru dan orangtua siswa untuk memeriksakan kesehatan siswa lebih lanjut. Pemeriksaan berkala dan peningkatan kesadaran menjaga kesehatan bersama sangat bermanfaat untuk mencegah penyakit berbahaya yang dapat merenggut jiwa generasi penerus bangsa.

Nilai presisi tertinggi sebesar $99,43 \%$, nilai terendahnya $94,86 \%$. Sementara nilai akurasi hasil pengukuran tertinggi sebesar $99,18 \%$ dan nilai terendahnya sebesar $96,46 \%$.

Penelitian ini diharapkan bisa meningkatkan kewaspadaan masyarakat terhadap pentingnya pemeriksaan berkala kesehatan kususnya terhadap anak-anak generasi penerus bangsa dan meningkatkan taraf kesehatan masyarakat pada umumnya. 


\section{Kesimpulan}

Hasil pengukuran dan analisa, kita dapat mengambil kesimpulan sebagai berikut:

1. Sistem pengukuran suhu dan deteksi kehadiran yang digunakan untuk proses monitoring ini dapat melakukan proses akuisisi data dengan baik, serta data yang terbaca pada mikrokontroller dapat dikirimkan ke komputer.

2. Dari hasil penelitian didapat pengukuran nilai error tertinggi sebesar $2,46 \%$, termasuk kategori pengukuran baik karena errornya dibawah 5\%.

3. Penelitian ini nilai presisi pengukuran tertinggi sebesar $99,43 \%$, nilai terendahnya 94,86\%. Nilai akurasi tertinggi sebesar $99,18 \%$ dan terendah sebesar $96,18 \%$.

\section{Daftar Pustaka}

[1] A. Wardiyah, Setiawati, and U. Romayati, "Perbandingan Efektivitas Pemberian Kompres Hangat dan Tepid Spoge terhadap Penurunan Suhu Tubuh Anak yang Mengalami Demam di ruang Alamanda RSUD dr.H Abdul Moeloek,"

Kesehat. Holistik, vol. 10, no. 1, pp. 36-44, 2016.

[2] Ishmatul Fajriyah, "Hubungan Pengetahuan Ibu dan Dukungan Keluarga Dengan Status Imunisasi TD Pada Sub PIN Difteri," J. Berk. Epidemiol., vol. 2, no. 3, pp. 404-415, 2014.

[3] "Kasus dbd di jateng capai 1204 kasus kepala dinkes bukan angka luar biasa," Jateng Tribun, 2019.

[4] P. M. D. Megha S Patel, Khayati M Kakkad, Snehal V Patel, Nayan J Patel, Vishesh I Patel, “A Comparative Study of Accuracy of Non-contact Infrared Thermometry and Axillary Digital thermometry in neonates," Gujarat Med. J., vol. 69, no. 2, pp. 103-104, 2014.

[5] M. Adhi, R. Hasan, F. Noman, S. F. Mahmood, A. Naqvi, and A. U. H. Rizvi, "Range for normal body temperature in the general population of Pakistan," J. Pak. Med. Assoc., vol. 58, no. 10, pp. 580-584, 2008.
[6] R. Alfanz, A. Nurhadi, and J. A.

Laksmono, "Perancangan dan

Implementasi Sistem Monitoring Produksi

Biogas pada Biodigester," J. Nas. Tek.

Elektro, vol. 5, no. 1, pp. 2-8, 2016.

[7] R. Aziz and . K., "Uji Performansi Kontrol

Suhu dan Kelembaban Menggunakan

Variasi Kontrol Digital dan Kontrol

Scheduling untuk Pengawetan Buah dan Sayuran," J. Nas. Tek. Elektro, vol. 4, no. 2, p. 215, 2015.

[8] G. A. Dinata, "RANCANG BANGUN

ALAT PENGUKUR SUHU TUBUH MANUSIA DENGAN NON-CONTACT THERMOMETER," UNIVERSITAS MUHAMMADIYAH YOGYAKARTA, 2017.

[9] S. Istiono Majid, Endang Dian Setioningsih, "Monitoring BPM, Suhu dan Respirasi Tampil PC via Bluetooth dan Pengiriman Data via SMS (Monitoring BPM dan Pengiriman Data via SMS," Politeknik Kesehatan Surabaya, 2018.

\section{Biodata Penulis}

Munaf Ismail, adalah staf pengajar Progam Studi Teknik Elektro Fakultas Teknologi Industri Universitas Islam Sultan Agung Semarang. Lulus Program Sarjana tahun 2003 Teknik Elektro Fakultas Teknik Universitas Diponegoro. Pada tahun 2015 menyelesaikan studi Magister Teknik Elektro di UNISSULA Semarang.

Sri Arttini Dwi Prasetyowati, adalah staf pengajar Progam Studi Teknik Elektro Fakultas Teknologi Industri Universitas Islam Sultan Agung Semarang. Lulus S3 Teknik Elektro tahun 2010 Fakultas Teknik Universitas Gadjah Mada. Fokus penelitian pada pengolahan sinyal.

Jenny Putri Hapsari, adalah staf pengajar Progam Studi Teknik Elektro Fakultas Teknologi Industri Universitas Islam Sultan Agung Semarang. Lulus Program Sarjana Teknik Elektro Fakultas Teknik Universitas Diponegoro tahun 2007. Pada tahun 2014 menyelesaikan studi Magister Teknik Elektro di ITS Surabaya. 